\title{
An Overview of Equal Educational Opportunities in Turkey: A Spatial Analysis of Classrooms in Rural and Urban Primary Schools
}

\author{
Nazli Gökçe ${ }^{1}$, Erdoğan Kaya ${ }^{1}$, Semra Günay Aktaş ${ }^{2}$, Yeliz Mert Kantar ${ }^{3}$ \\ ${ }^{1}$ Faculty of Education, Anadolu University, Eskisehir 26470, Turkey \\ ${ }^{2}$ Faculty of Tourism, Anadolu University, Eskisehir 26470, Turkey \\ ${ }^{3}$ Department of Statistics, Anadolu University, Eskisehir 26470, Turkey \\ Correspondence: Yeliz Mert Kantar, Department of Statistics, Anadolu University, Eskisehir 26470, Turkey.
}

Received: November 20, 2016

Accepted: December 9, 2016

Online Published: December 13, 2016

doi:10.11114/jets.v5i1.2069

URL: http://dx.doi.org/10.11114/jets.v5i1.2069

\begin{abstract}
The number of students in a class is a primary factor affecting the quality of education. Therefore, this study examines the distribution of the number of students per class in rural and urban primary schools in Turkey, and efforts have been made to specify classroom needs. Statistical data was obtained from the Turkish Institute of Statistics and the Ministry of National Education. In order to better interpret data, graphs and maps were prepared with the help of GIS. The MapInfo 12.0 program was used for map drawing. The data was mapped using the Inverse Distance Weighted Algorithm. Whether there was global clustering regarding the distribution of the number of students per class in both rural and urban primary schools in Turkey was investigated using Moran I. In addition, local Moran I maps were employed to identify whether or not there was local clustering or neighboring interaction. At the end of the research, a variety of findings and results were obtained regarding the condition of primary school classes in Turkey. In conclusion, it has been determined that there is a need for more classes in certain regions, while they are urgently needed in others.
\end{abstract}

Keywords: Turkey, rural, urban, primary school, classroom, student, spatial statistic, geographical information system

\section{Introduction}

\subsection{An Introduction to the Problem}

Primary schools in Turkey form a crucial part of primary education, which is an educational step where pupils are provided with basic, but important, knowledge, skills, good behavior, and habits that every citizen should have. Low-level basic skills an individual needs in order to participate in social, economic, and political life are given in primary education. These skills include literacy, expressive language skills, maths, and problem-solving activities. In addition, this step aims to furnish students with various attitudes, values, and knowledge (Başaran, 1996; Webster, 2000). The legal basis for the notion 'primary education', used by UNESCO in the 1950s, is people's right to an education. Hence, Article \#26 of Universal Declaration of Human Rights states that "Everyone has the right to education. At least primary and basic level education has to be free." In Turkey, the $24^{\text {th }}$ Article of the Constitution states, "Primary education is mandatory for all male and female citizens, and it is free in government schools." This Article emphasizes the obligation for individuals to have a primary and basic level education, and it is the responsibility of the government to provide such education. The duration and scope of compulsory education are defined in each country's own laws and constitution and across international declarations and contracts. For instance, as specified in the 1948 Universal Declaration of Human Rights (Article 26), the 1959 United Nations Convention on the Rights of the Children (Article 7), and the World Declaration on Education for All, a child has at least the right to free and mandatory primary education, and such primary education is considered to be compulsory. These articles lay emphasis on improving a child's independent reasoning skills, talents, moral, and social responsibilities and developing him/her into a socially beneficial individual.

In Turkey's Basic Law of National Education (1973), there is a statement which reads, "Elementary schools consist of a five-year first step and a three-year second step", namely, primary and secondary school. Described as basic education, this step has turned into 'Primary Education' according to the $7^{\text {th }}$ Article of Law\#2842, enacted in 1983. Following this, with the amendment Law \#4306 legislated in 1997, "Primary schools have become eight-year mandatory schools. 
These schools provide a continuous education, and those who manage to graduate are given certificates of primary education" (MNE, 2006). However, according to the Law\#6287 enacted in 2012 (Primary and Educational Act), the compulsory education period was extended to 12 years (Ministry of National Education, 2012). Based on this law, schools were divided into primary, secondary, and high schools in accordance with a graded educational plan (4+4+4) and primary schools started to serve either as only primary or secondary schools, or both at the same time, depending on physical capacities. As a result of this plan, the spatial capacity of schools became a controversial topic. All these developments entailed a re-evaluation of the physical capacities of primary schools in Turkey. As a main indicator of the physical capacity of primary schools, classrooms are discussed in this study.

The number of students per class is a substantial indicator which shows the physical capacity of primary schools in Turkey. It is known that in Turkey there is no equal distribution of students per classroom; some schools have overcrowded classrooms, whereas some have multi-grade or uncrowded classrooms leading to mobile teaching. Though this classroom issue has been evaluated in numerous studies (Akkalkan, 2009; Karakutuk \& Tunc, 2004), it is still an on-going problem in Turkey.

According to a number of social scientists, classroom size affects a student's self-confidence, co-operation, sense of belonging, and behavioral changes. While a small classroom environment means reinforcing participation and ever-growing attention for students, larger sizes minimize interaction with the teacher, and students may become passive. Psychologists and sociologists identify that students from bigger groups feel less responsibility for group tasks and are prone to social time-wasting compared to those in smaller groups. They advocate that there should be a balance across classes and that thirty students in a class can be accepted as crowded with seventeen to twenty being an ideal size (Finn, et al. 2003). More problems emerge and the quality of education decreases as class numbers grow bigger. Crowded classes prevent teachers from fulfilling their functions at length. Over-populated classes especially hinder reading, maths, problem-solving, and critical thinking skills, and teachers experience difficulties while helping students when classes have too many students (Ogulmus \& Ozdemir, 1995). In addition, an authoritative teacher profile, considered necessary for crowded classes, puts distance between students and teacher. Therefore, a mutual trust atmosphere cannot be established or is delayed, which leads to teacher-centered instruction and a rote learning environment (Y1lmaz \& Altınkurt, 2011).

There are various opinions regarding the ideal number of students in a classroom, which varies depending on a number of factors, such as topic of study, methodology and techniques employed by the teacher. However, some research has concluded that the ideal number of students in a classroom should be between twenty to thirty, and that any class containing more than 30 students should be considered over-populated (Baytekin,2001; Finn at al., 2003; Finn, 2002 cited in Guclu, 2002; Isik, 2004; Karacali, 2006; Onder et al. 2013; Yaman, 2006). Considering the wealth of relevant research and Turkey's conditions, this study regards twenty five as the ideal number of students for class size.

Numerous studies have been conducted to evaluate the condition of primary school classrooms across various provinces in Turkey (Akbulut, 2010; Akpinar and Akbulut, 2011; Sahin, 2006; Temiz, 2007). However, no comprehensive study has been made into the current condition of classrooms in the provinces and county towns. In fact, analyzing the number of students per class in primary schools is significant both in terms of depicting the present situation and for developing future strategy.

Currently, Geographic Information Systems (GIS) is a technology commonly utilized in the preparation of educational plans. The use of land, for such purposes as traffic security or school services, can easily be planned through GIS. In this sense, school designs can be developed based on both the current and the predicted student population and the school's interaction with its environment (Willson, 2008, p. 238). Spatial statistics and spatial analysis are a fundamental component of GIS, and they are used to explain spatial patterns or spatial relationships. As for the field of education, there is little empirical research in the literature which attemps to understand the difference between geographical areas in terms of educational opportunities. For example, Grześkowiak (2015) studied the similarities or otherwise of educational processes in Poland using spatial statistical tools such as Moran I and LISA. Ahmet (2011) analyzed the relationship between the spatial clustering of income and education in certain districts of Pakistan by employing a spatial exploratory data analysis technique. Elias and Rey (2011) explored the issue of educational convergence in Peru over the period 1993 to 2005 using both exploratory spatial data analysis and spatial econometrics. Fuente et al. (2013) researched spatial distribution of educational facilities in Chile.

The primary aim of this study is to analyze the spatial distribution of students per class in both rural and urban schools in Turkey using local and global Moran I statistics, a spatial statistics method of GIS, and to determine the distribution of classroom need. Moran I was employed to identify if there was a global problem in Turkey based on data obtained from the Turkish Institute of Statistics and the Ministry of National Education, while local Moran I maps (LISA: Local Indicator of Spatial Association) were utilized to discover if there was any neighboring interaction or local 
clustering. In addition, the situation of rural and urban areas that are in need of classrooms was analyzed on a needs map accompanied by relevant interpretations. Accordingly, answers have been sought for the following research questions:

- What is the distribution of students per class in rural primary schools in Turkey?

- Do the distributions of both crowded and uncrowded classrooms in rural primary schools of Turkey form statistically significant spatial clusters?

- What is the distribution of students per class in urban primary schools in Turkey?

- Do the distributions of both crowded and uncrowded classrooms in rural primary schools of Turkey form statistically significant spatial clusters?

- What is the distribution of classroom need across rural primary schools in Turkey?

-What is the distribution of classroom need across urban primary schools in Turkey?

\section{Method}

\subsection{Research Model}

This study has been completed through a survey model. All of the relevant data was taken from the Ministry of National Education (MNE) and the Turkish Statistical Institute (TIS). In particular, the data considering the number of students per class in primary schools during 2013 was analyzed. There are two reasons for this decision. Firstly, primary and secondary schools were again split from the umbrella scope of primary education during the academic year of 2012-2013. Secondly, MNE and TIS have the most comprehensive and reliable data regarding the number of students per class for the same academic year. During an examination of the number of students per class in rural and urban districts, TIS criteria for rural and urban districts were employed. According to TIS, county towns are urban areas and settlements in all rural areas are villages. In this regard, rural and urban schools were separately studied for each county.

\subsection{Data Collection, Analysis, and Map Drawing}

A database was built on MapInfo 12.0 based on the data obtained from TIS and MNE. Using this software, maps were drawn in order to see the total distribution of students per class in both rural and urban primary schools across all county towns and to make relevant comparisons. The color red was selected to mark the difference in student numbers. Colors degrading towards white signify county towns where classes are not crowded. On the other hand, shades towards dark red point out classes in those counties which are crowded. The intervals across numbers of students per class were determined through a natural breakpoint method on the maps. In this method, software data is split into intervals at points where there is a natural break. Darker red coloring indicating higher numbers of students per class in rural and urban primary schools was arranged in accordance with the literature by the researchers. The Inverse Distance Weighting (IDW) algorithm was utilized when drawing up these maps.

IDW is a simple interpolation technique for the estimation of the value of non-sampled locations. This technique uses a weighted average of the values of nearby locations to estimate the value of the location where there is no sample. The weight of a particular point is assigned in the averaging calculation which depends upon the distance between sampled locations and the non-sampled location.

A general form for finding an unknown value at a given location based on the values of nearby locations is given as follows:

$$
u=\left\{\begin{array}{l}
\frac{\sum_{i=1}^{k} w_{i} u_{i}}{\sum_{i=1}^{k} w_{i}} d(i, j) \neq 0, \\
u_{i}, d(i, j) \neq 0
\end{array}\right.
$$

Where $w_{i}$ is the weighting function and $d(i, j)$ is the distance measure between locations $i$ and $j$. Thus, values for unknown points in the whole region are assigned with the weighted arithmetic mean of the available values at the known points.

Secondly, Global and Local Spatial Autocorrelation analyses were conducted using a GeoDa program in order to check if either crowded or uncrowded classes in rural and urban primary schools accumulated to form statistically significant clusters (county towns that are uncrowded, crowded but neighboring an uncrowded one, or neighboring a crowded one) across the county towns. Spatial distribution and spatial clusters in terms of the number of students per classroom are shown for rural and urban primary schools in Turkey for the year 2013. It is known that the first law of geography states 'everything is related to everything else, but near things are more related than distant things'. Spatial autocorrelation can be simply defined as a correlation of one variable with other variables throughout space. Most data generally involves geographic location information, and thus, it is necessary to test the data for spatial autocorrelation. A number of spatial 
statistics tools are available for the test whether there is spatial randomness or not. The well-known global spatial autocorrelation is Moran I with a formula given as follows:

$$
I=\frac{n}{\sum_{i=1}^{n}\left(x_{i}-\bar{x}\right)^{2}} x \frac{\sum_{i=1}^{n} \sum_{i=1}^{n} w_{i j}\left(x_{i}-\bar{x}\right)\left(x_{j}-\bar{x}\right)}{\sum_{i=1}^{n} \sum_{i=1}^{n} w_{i j}}
$$

where $n$ is the total number of spatial observations (i.e. locations), $x_{i}$ is the value for the spatial location $i, x_{j}$ is the value for another spatial location $j, \bar{x}$ is the mean value of all locations, and $w_{i j}$ is an element of spatial weight matrix applied for a comparison between locations $i$ and $j$. The potential interaction between two locations, regions, states or even countries is presented as a weight matrix in spatial analysis. The weight matrix can be expressed by distance or contiguity matrix. The weight matrix may be different depending on specified contiguity, distance band or number of neighbors. However, there is no precise agreement about the type of weight matrix to be operated for spatial analysis (Anselin, 1995). In the spatial $N$ by $N$ weight matrix, each element $w i j=1$ when $i$ and $j$ are neighbors and $w i j=0$ otherwise, the diagonal elements of the matrix are set to zero.

There is positive spatial autocorrelation if high values of one variable at one location are associated with high values at a neighboring location. Generally, if the Moran I is greater/less than 0, it is interpreted as positive/negative autocorrelation. If the Moran I value is zero, then no spatial autocorrelation is present.

Similarly, the local Moran I statistics is a well-known local spatial autocorrelation measure. Based on local Moran I statistics, local spatial autocorrelation analysis (LISA) is conducted (Anselin, 1995). A LISA map is drawn to identify potential local clusters and spatial outliers. While the LISA significance map shows locations with significant the local Moran I statistic, the LISA cluster map provides essentially the same information as the significance map, but shows significant locations in color, interpreted by the type of spatial autocorrelation. High-high (HH) and low-low (LL) regions show clustering of similar values of the considered variable, while high-low (HL) and low-high (LH) regions indicate outliers. Blue colored areas assigned on the map indicate low values, which are again surrounded by low values (LL), forming a statistically significant pile. On the other hand, red colored areas show high values which are surrounded again by high values $(\mathrm{HH})$, forming a statistically significant pile. Lastly, uncolored areas provide locations where there is no statistically significant pile.

Lastly, new maps were drawn in order to see the entire distribution of classrooms in rural and urban schools across all the county towns in Turkey, and to be able to hold relevant comparisons. A total of twenty five students, which is quite common and an acceptable number for Turkey, was set as the criteria for classroom needs after analyzing ideal classroom sizes in the literature. In each county, the ideal number of classrooms was calculated for all rural and urban schools (Adequate Number of Classrooms $=$ Number of Students / 25). Next, this number was subtracted from the present number of classrooms, and how many classrooms were needed or how many were extra was determined (The Number of Classrooms Needed $=$ The Number of Present Classrooms-Adequate number of Classrooms). On all the maps, a color code was utilized in order to depict various levels of need for classrooms. A light blue color points out an extra number of classrooms while a dark blue color refers to an excessive number of classes. Green was selected to represent places where there was no need for new classes. The color yellow indicates an insufficient number of classrooms, while red indicates too few classrooms. Considering the intervals between numbers showing the need for classrooms on these maps, the researchers, as a start point, predicted a value acceptable under conditions prevailing in Turkey with respect to the number of classrooms in rural and urban schools. Subsequently, intervals were determined by taking the highest and lowest numbers into consideration.

\section{Findings}

\subsection{The Spatial Distribution of the Number of Students per Classroom in Rural Schools in Turkey}

Figure 1 shows the distribution of the number of students per classroom in rural schools of Turkey. As can be seen in Map 1, the number of students per class is more than twenty five in some rural primary schools in several provinces located in East and South East Turkey, such as Sirnak, Hakkari, Van, Mus, Erzurum, Agri, Kars, Igdir, Sanliurfa, Diyarbakır, Gaziantep, Kilis, Kahramanmaras, and Osmaniye. Furthermore, this number is again higher than twenty five for some primary schools located in other regions; in particular, Istanbul, Sakarya, Zonguldak, Isparta, Aksaray, Nevsehir, and Nigde. Contrary to this, classroom size is lower than ten students in the Marmara Region (Edirne, Kirklareli, Balikesir, and Bursa), the Aegean Regions (Denizli), the Central Anatolian Region (Eskisehir, Ankara, Cankiri, Yozgat, Kirsehir, Kayseri, and Sivas), the Black Sea Region (Kastamonu, Sinop, and Artvin), and the Eastern Anatolian Region (Erzincan andTunceli).

The map shows that the distribution of the number of students per class in rural primary schools is unbalanced within Turkey. While this number is quite high, especially throughout the entire Eastern and South-East Regions, it drops below ten for some districts of the Mediterranean, Central Anatolia, Aegean, and Black Sea Regions. It would be wise 
to take this data into consideration for future classroom investment and for further educational planning in Turkey.

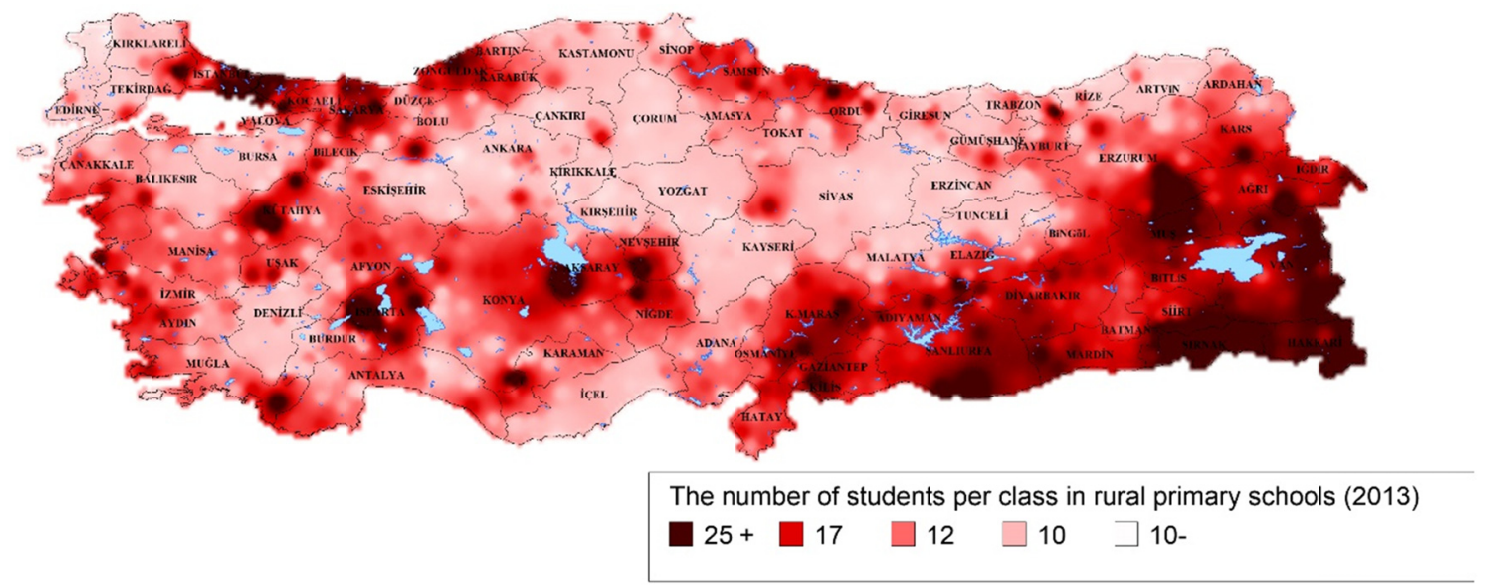

Figure 1. The distribution of the number of students per classroom in rural primary schools of Turkey

In addition, the results of spatial statistics for the number of students per classroom in rural primary schools show that the observed spatial autocorrelation for rural areas is 0.18 ( $p$-value $=0.001)$, which indicates a medium- level of spatial clustering of SPC (see the graphic in the bottom right corner of Figure 2). Its $p$-value is 0.001 , showing significant statistics. In order to further detect the contribution of each rural area to global spatial autocorrelation, local correlation analyses should be performed. As mentioned previously, the local indicator of spatial association (LISA) shows local spatial clusters. A LISA map for rural areas is given in Figure 2.

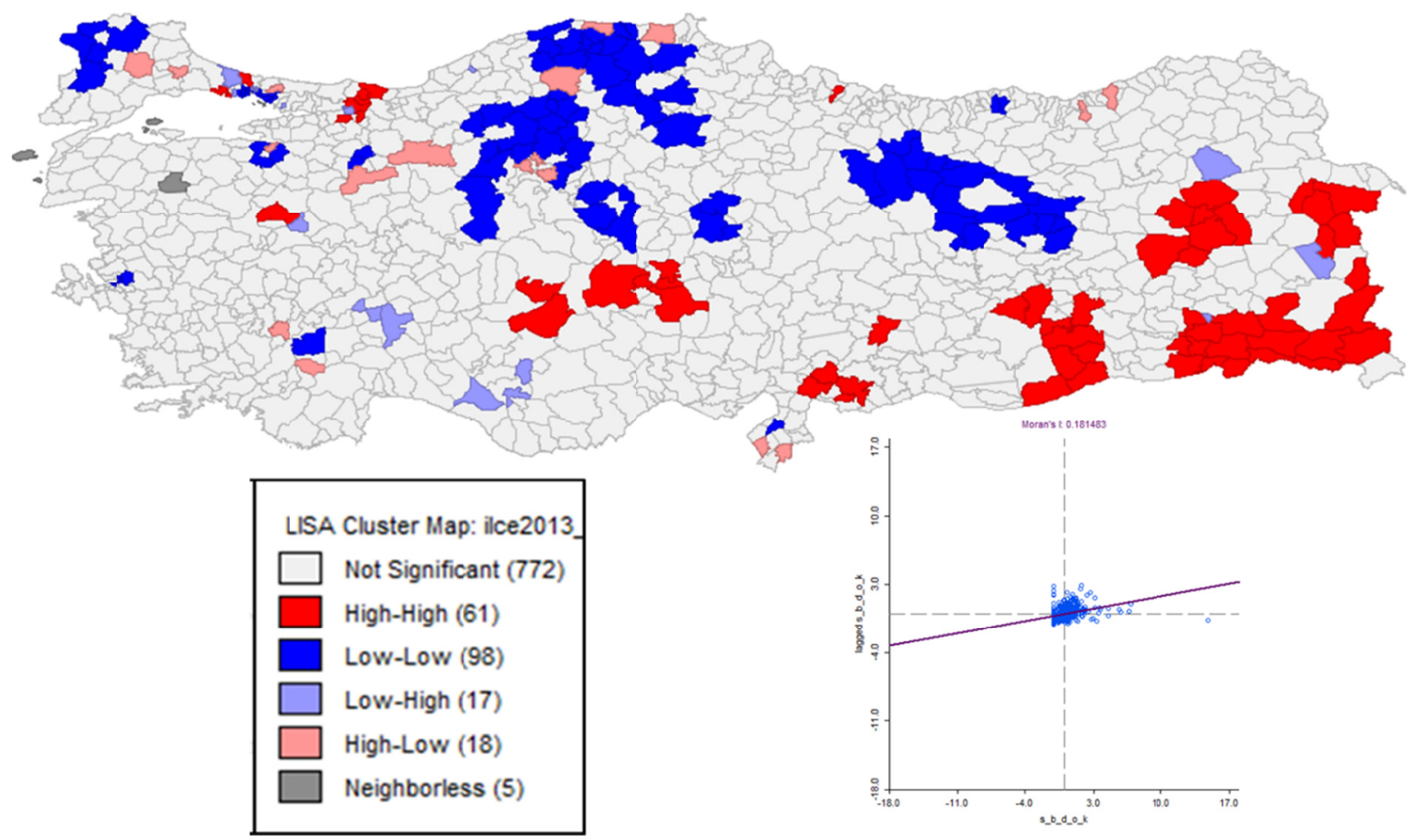

Figure 2. Moran cluster maps and Global Moran I value for the spatial autocorrelation for the number of the students per class (SPC) in Turkey in rural areas. (5\% pseudo-significance level)

Figure 2 depicts statistically significant spatial clusters, either crowded or uncrowded, with respect to the number of students per class in rural primary schools. There are six significant clusters with High-High (HH) in the Eastern part of Turkey, an underdeveloped region, with low ratios, not only in education, but also in social and professional life. Three small clusters are seen in the Central Anatolia region. On the other hand, it is interesting that large rural areas in Adapazari province present $\mathrm{HH}$ clusters. Moreover, two rural areas in Istanbul are $\mathrm{HH}$ clusters reported at $1 \%$ level. Most of the sub-regions, such as the Thrace Peninsula, the Central Anatolia region, and the Black Sea region have LL clusters which indicate that low values are surrounded by low value neighbors. These blue areas present that the number 
of students in a class is low. As can be seen, another fact that the map indicates is that classroom investment is not based on a well-structured plan, particularly in the South East, East, Black Sea, Central Anatolia, and Marmara regions.

\subsection{The Spatial Distribution of the Number of Students per Classroom in Urban Schools of Turkey}

Figure 3 displays the distribution of the number of students per classroom in urban schools of Turkey. This number is higher than the ideal, particularly in the east and south eastern regions. The number of students per class is more than thirty two in several urban areas, such as Sanliurfa, Diyarbakir, Adiyaman, Gaziantep, Kilis, Sirnak, Hakkari, Mus, Erzurum, Agri, Kars, and Igdir. Towards the north of the country, around the province of Zonguldak, this number increases, and in some other provinces (the capital Ankara, Istanbul, Sakarya, Izmir, and Isparta) the number of students per class in urban primary schools exceeds thirty two. However, this number decreases below seventeen in other regions, such as the Thrace Peninsula (provinces of Edirne and Kirklareli), Aegean (provinces of Kutahya, Usak, and Denizli), Central Anatolia (provinces of Eskisehir, Yozgat, Kirsehir, and Kayseri), and the Black Sea region (Kastamonu, Sinop, Corum, and Rize). It can be deduced from Figure 3 that the distribution of the number of students per class is also not consistent for urban primary schools in Turkey.

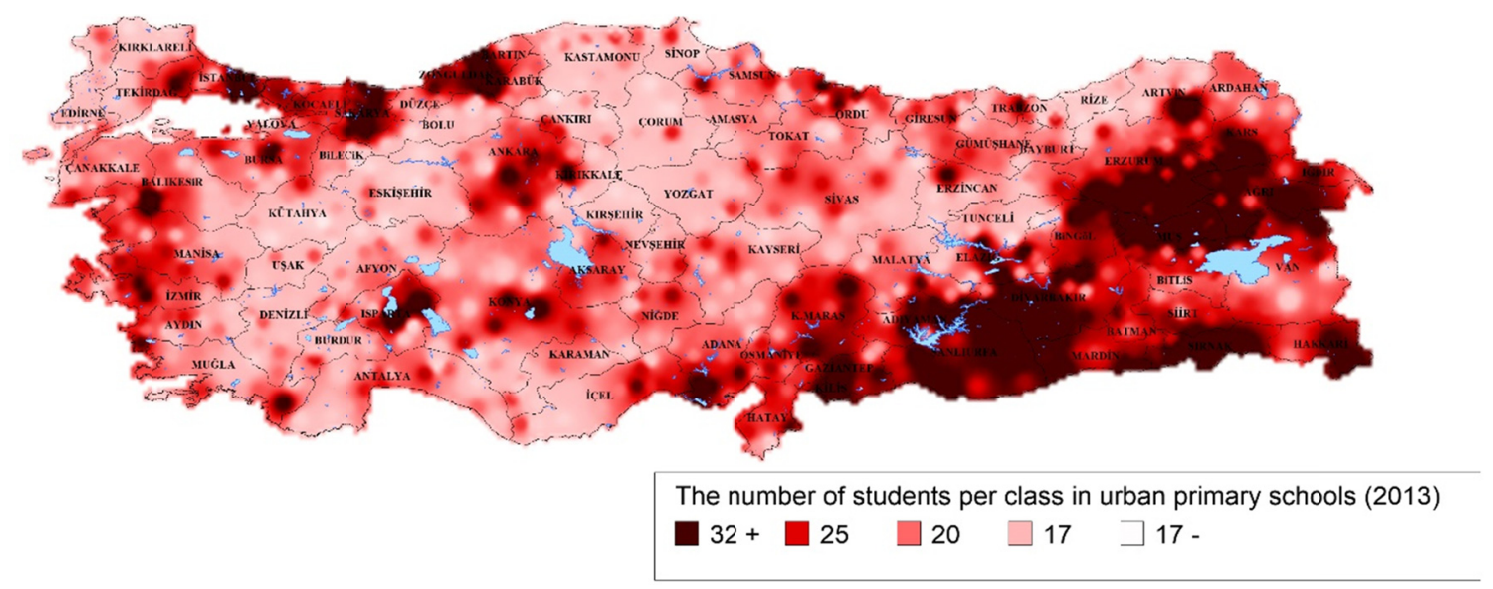

Figure 3. The distribution of the number of students per class in urban primary schools in Turkey

Map 4 shows that there are statistically significant spatial clusters, either crowded or uncrowded, with respect to the number of students per class in urban primary schools. Similar to rural areas, there is no high global spatial autocorrelation $(0.13)$ between the provinces in Turkey. The $p$-value of the spatial autocorrelation is 0.01 (See bottom right corner of Figure 4). Therefore, we should look at local autocorrelations. Similar to the case in rural areas, a HH cluster is seen in Istanbul, Adapazar1, Zonguldak and the South Eastern Anatolia region, and the Eastern Anatolia region.

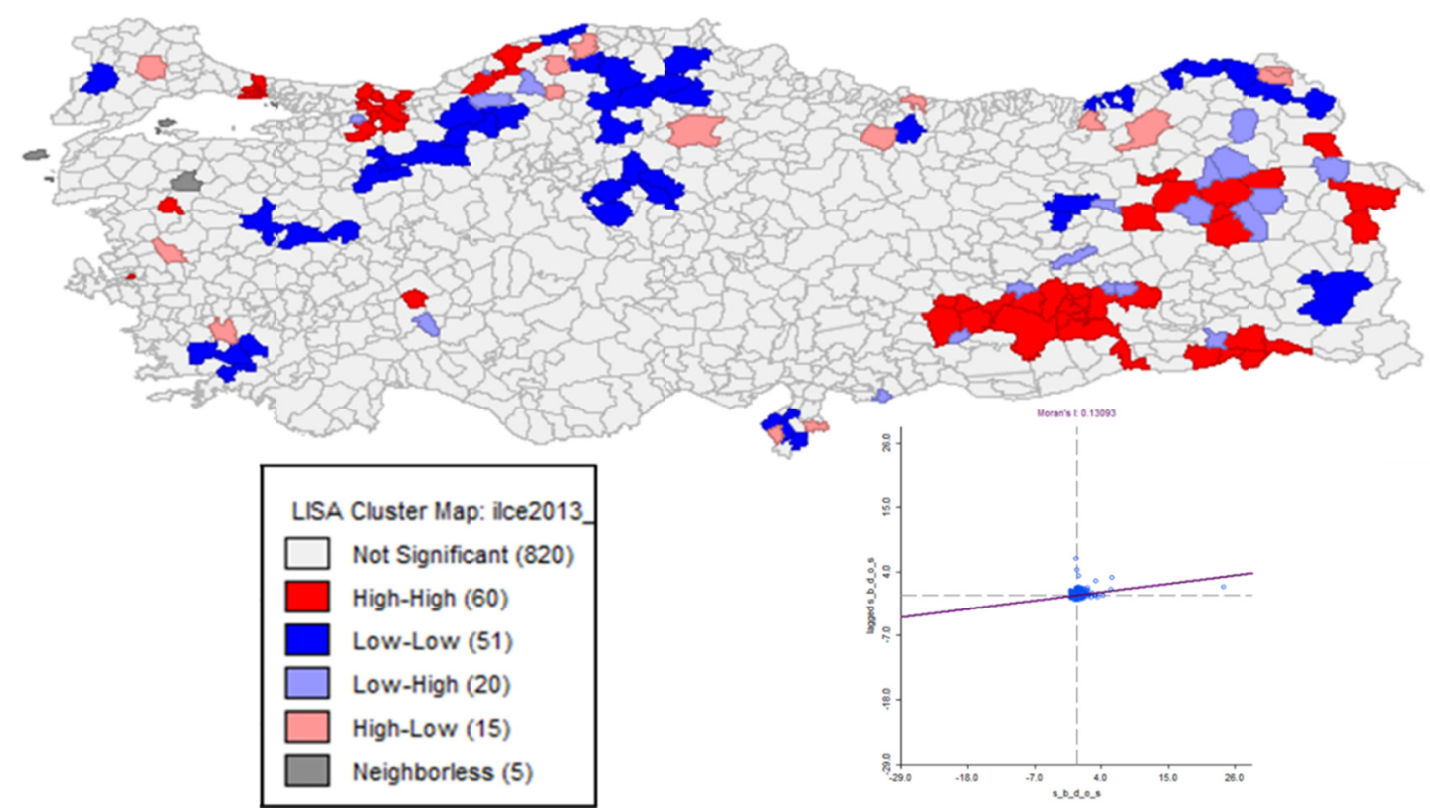

Figure 4. Moran cluster maps and Global Moran I value for spatial autocorrelation for the number of students per class in Turkey for urban areas. (5\% pseudo-significance level) 
Taking urban areas into account, it should be noted that the LL clusters are located in the Western Black Sea region, in Central Anatolia and in the Aegean regions. Most of the sub-regions shown in white have no significant spatial autocorrelations in the map. Other values described as spatial outliers (HL and LH) are indicated in pink and purple, respectively. HH clusters in Istanbul, the Western Black Sea region and particularly in eastern regions show the worst regions in terms of the number of students per class (SPC). This dramatic result is valid for the eastern part of Turkey, which is an underdeveloped region in terms of various social and economic indicators.

\subsection{The Spatial Distribution of Classroom Need across Rural Primary Schools in Turkey}

Figure 5 shows the distribution of classroom need across rural primary schools in Turkey. As can be seen from Figure 5, the number of classrooms in some rural primary schools is either less or more than is needed. However, the rural areas where classroom need is serious are greater in number than those with no need for classes. Rural primary schools with a significantly insufficient number of classrooms are spread throughout all regions.

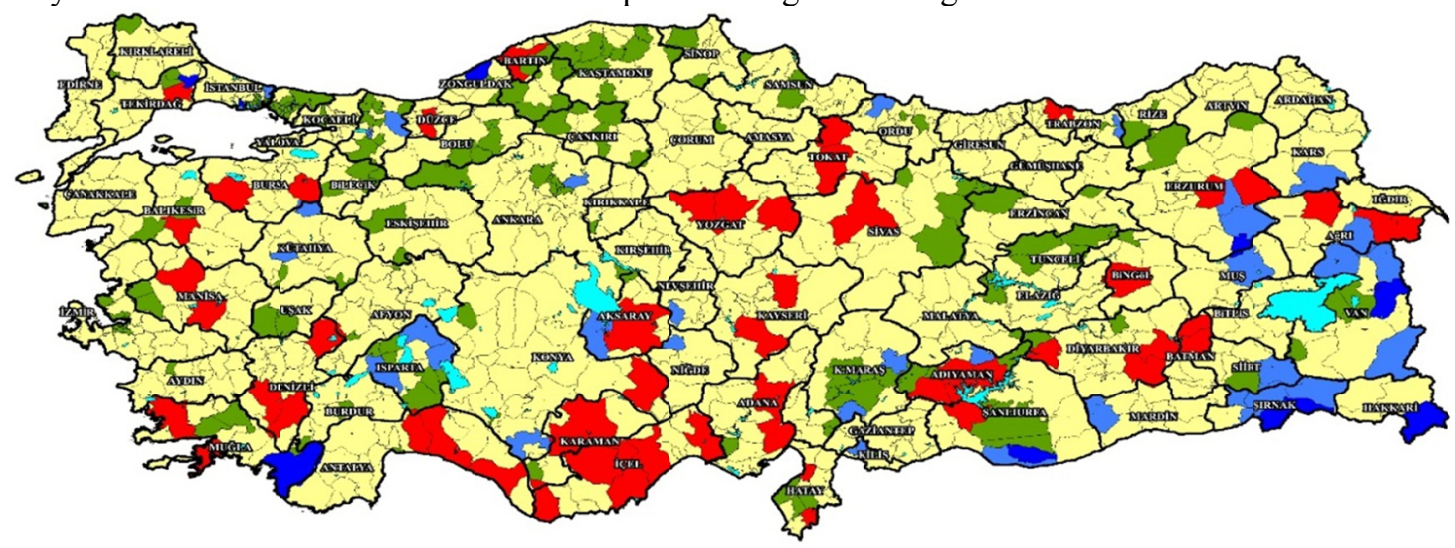

$$
\begin{aligned}
& \begin{array}{c}
\text { Classroom need across rural primary schools } \\
(2013)
\end{array} \\
& \begin{array}{clc}
\text { (The number of Counties) } \\
120-354 & \text { Highly insufficient number of classrooms } \\
3-120 & \text { Insufficient number of classrooms } & (706) \\
-3-3 & \text { Sufficient number of classrooms } & (164) \\
-51--3 & \text { Excessive number of classrooms } & (39) \\
-146--51 & \text { Highly excessive number of classrooms } & (10)
\end{array}
\end{aligned}
$$

Figure 5. The distribution of classroom need across rural primary schools in Turkey

Important data displayed on Map 5 and shown in Figure 5 indicates that some provinces, especially in the east and South Eastern Anatolia region, such as Sirnak, Hakkari, Mus, and Sanliurfa, have more classrooms than is necessary in rural primary schools. Although not that common, certain other rural primary schools in Mugla, Isparta, and Zonguldak also possess more classes than required. The fact that some rural primary schools have more classrooms than necessary while others are in need of more classes indicates a lack of planning in terms of investment and development. On the other hand, it should also be noted that a number of the rural areas in the east and south eastern regions have been deserted due to security concerns. Lastly, an excessive number of classrooms in the rural schools located in the east and south eastern regions should be considered as a positive sign of efforts to provide educational opportunities in small villages with a few students.

\subsection{The Spatial Distribution of Classroom Need across Urban Primary Schools in Turkey}

Figure 6 shows the distribution of classroom need across urban primary schools in Turkey. The map shows that some of the urban primary schools have more classrooms than is necessary while others have insufficient. Yet, one can say that the number of urban schools with more classrooms than is necessary is larger than those that need new classes. Those having a significantly insufficient number of classes mostly cluster around Edirne, Istanbul, Bursa, Duzce, Bilecik and Bolu in North West Anatolia.

According to Figure 6, all regions, except for South East Anatolia, are in need of classrooms. Even this region though has the highest amount of urban primary schools with more classrooms than is necessary. However, an overall analysis of the map indicates that the number of classrooms in urban primary school is not a serious problem in Turkey. Again, the fact that some schools have more classrooms than they need and some others suffer from a lack of adequate classrooms indicate that relevant investment should be conducted based on a proper plan. 

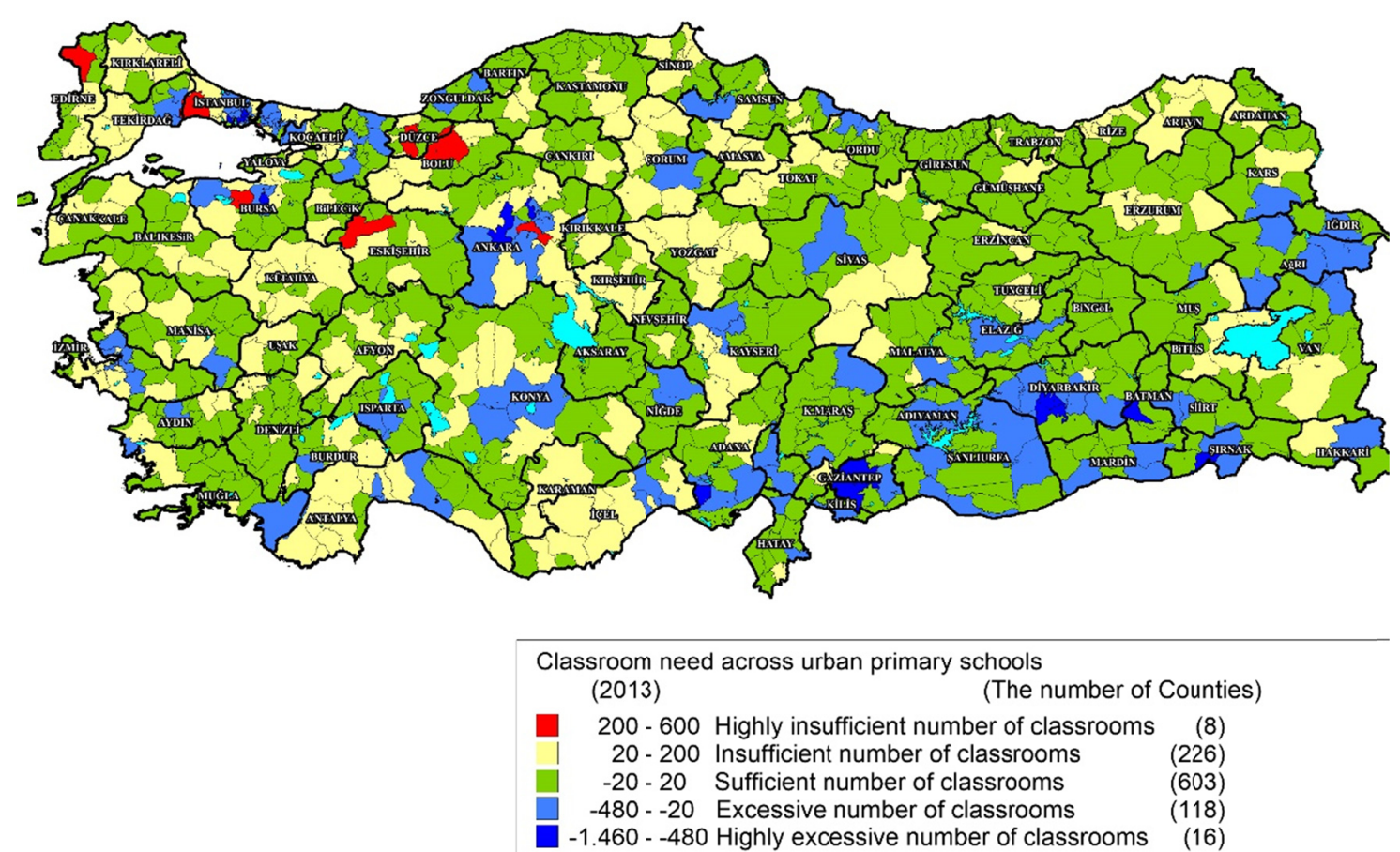

Figure 6. The distribution of classroom need across urban primary schools in Turkey

\section{Discussion and Conclusion}

An even distribution of students per class matters a great deal in order to establish equal opportunities and to improve the quality of education at the primary level in Turkey. Enacted in 2012, the 'Education and Primary Education Law \#6287' mandates that a twelve year primary education is compulsory for every citizen (Ministry of National Education, 2012). Based on this law, several changes were put into practice, such as the initial merging of primary and secondary schools and then separating them again. Massive student transfers carried out during the merging and separating turned the physical capacities of schools into a hot debate issue. Therefore, this study examines the number of students per class in rural and urban primary schools. The distribution of students per class in rural and urban primary schools has been shown on maps based on the data set relating to the academic year of 2013-2014. Whether there is a global problem with respect to the distribution of students per class in rural and urban primary schools in Turkey is analyzed via Moran I, while local Moran I maps (LISA - Local Indicator of Spatial Association) have been employed in order to determine if there is a neighboring interaction among local clusters. At the end of the study, the need for classrooms has been identified based on the number of students per class in rural and urban primary schools in Turkey, and relevant distributions have been shown on maps.

The findings indicate that the distribution of students per class in both rural and urban schools is not even and that classrooms in some provinces are crowded while those in other places are uncrowded. Moran I reported problems concerning the distribution of students per class in rural and urban primary schools, and LISA maps have resulted in neighboring interactions among local clusters. According to the results of the study, the number of students per class in many rural and urban primary schools located in the east and south eastern regions of the country is far greater than the ideal class size. Moreover, the number of students per class is highest in Istanbul, Ankara and Izmir, which are the largest provinces in terms of population and economy, in Artvin and Zonguldak in the Black Sea region, and in Aksaray, Konya, Nevsehir, and Isparta in the central regions. The literature contains many research studies supporting these results, which clearly indicate that the number of students per class is excessively high throughout Turkey (Aydın et al. 2012; Çingi et al., 2008). Yllmaz \& Altınkurt (2011) report that the number of students per class was thirty four during the 2008 to 2009 academic year. According to their study, Batman is the province with the highest number of students per class (50). However, this number is either sixty or above in highly populated cities such as Istanbul and in rapid growing cities located in the eastern part of the country. Likewise, other studies note that this number is highest for Istanbul (53), the South East Anatolia region (50), the East Anatolia region (38) (Sarieer, 2010), and reaches forty three students in provinces such as Sanliurfa, Diyarbakir, Mardin, Kahramanmaras, Van, Igdir, Isparta, Zonguldak, Aksaray, and Nevşehir (Kucukyilmaz et al. 2015). Furthermore, this number is higher than ideal even in regions with the lowest number of students per class, such as Western Marmara (25), Black Sea (25), Central Anatolia (26), and the Aegean regions (29) (Sarıer, 2010). Aydın at al. (2012) report that the average number of students per class is 27.2 in Turkey, 
whereas it is 15.9 in Finland, one the most successful countries in terms of education. Similar to the present study, many others also have concluded that educational opportunities offered to students in primary schools vary considerably across regions, provinces, and even counties (Cingi et al., 2008; Wordbank, 2005).

In Turkey, both schools and classes are excessively crowded, especially in rapidly growing cities. As stated by Ogulmus \& Ozdemir (1995), "classes with 70, 80, or 100 students deprive schools of their identities as educational institutions and turn them into warehouses or factories where young people are kept for a period." This accumulation is the leading factor of low level quality. In large cities like Istanbul, there are some classes where three to four students are stacked into rows that can barely host two students, where some students have to stand, and where teachers cannot even walk around the classroom. Since adequate student-teacher interaction cannot be effectively established, conducting a qualified educational process in these classes is not possible even with the best teachers, programs, and educational materials. There have been several studies which clearly report that crowded classes impede student-teacher interaction and hinder the quality of education (Aydıner, 2006; Berberoglu \& Kalender, 2005; Dincer and Kolasin, 2009; Gedikoglu, 2005; Yilmaz and Altınkurt, 2011). As a result, an uneven distribution of students per class and an excessive number of students in some provinces are the most significant factors impeding equality of opportunity in education. Therefore, it is of paramount importance to determine the classroom need in rural and urban settlements where classes are crowded and to plan future investment accordingly.

This study identifies the amount of classrooms needed for settlements where classes in rural and urban primary schools are crowded, and the relevant findings are shown on maps. In this sense, all rural primary schools in each region are in need of classrooms in Turkey. In addition, urban schools, especially in the Marmara and Central Anatolia regions, where large populated cities are located, also need more classrooms. The maps (Figure 5 and 6) show that classrooms in certain rural areas are insufficient in number to meet the need: (Van and Bingol in the east; Hakkari, Sirnak, Sanliurfa, Diyarbakir, and Adiyaman in the south east region; Aksaray and Nevsehir in Central Anatolia; Duzce in the Black Sea region; and Istanbul in the Marmara region). In addition, the LISA map (Figure 2) indicates that the aforementioned provinces in the east and south eastern regions are surrounded by other crowded provinces, which means that mobile education cannot solve the problem. Thus, these areas should have priority in terms of the elimination of problems regarding the distribution of classrooms across primary schools. Kocberber and Kazancik (2010) conclude that the east and South Eastern Anatolia regions obviously have educational needs in terms of teachers, classrooms, and information technology. As shown in the maps, the distribution of classrooms across rural and urban primary schools is uneven throughout Turkey, but some urban schools located in the Black Sea region, the Aegean, central Anatolia, and the Eastern Anatolia regions have more classrooms than necessary, which is clearly a waste of resources in terms of investment.

Several studies in the literature pinpoint that classrooms in Turkey are too few to meet the present need, that the number of classrooms remain the same although schools get more and more crowded every year (Sar1er, 2010), and that the quality of education is impeded due to a mandatory double shift schooling as a result of an insufficient number of classrooms (Kavak, 2009; Yılmaz and Altınkurt, 2011). School and classroom investment should be planned and organized in accordance with needs. Therefore, the results of this study can be used to assist in the making of relevant decisions.

One noteworthy finding of the present research is that the number of students per class in some rural areas has dropped below ten in Turkey. Rural schools located in the following provinces in particular have the least number of students per class: Edirne, Kirklareli, and Tekirdag in Thrace Peninsula; Balikesir and Bursa in the south Marmara region; Denizli in Central West Anatolia; Eskisehir, Ankara, Çankiri, Kirikkale, Kirsehir, Yozgat, Kayseri, and Sivas in Central Anatolia; Burdur and Icel in the Mediterranean region; and Kastamonu, Sinop, Corum, Tokat, Giresun, Trabzon, Rize, and Artvin in the Black Sea region. This results in either multi-grade teaching which stipulates that students at different grades are educated in the same class or mobile teaching which means transferring students from different places to a school. However, several studies report that these two solutions are not free from problems. Primarily, it is stated that multi-grade teaching has the most profound negative effect over student success (Aydın et al. 2012; Gedikoglu, 2005; Yılmaz \& Altınkurt, 2011). Koçberber and Kazancık (2010) explain that the practice of mobile teaching, regarded by many as an opportunity for education, actually creates a serious burden on the country's economy and emphasize that each student should have access to every educational opportunity where they reside. Therefore, establishing an even distribution of students per class in Turkey is also important in order to eliminate problems caused by both multi-grade and the practice of mobile teaching. On the other hand, uncrowded classes in rural primary schools should not be considered a financial burden. Rather, they should be seen as a positive investment in rural areas in accordance with the principle of a social state.

Relevant research pinpoints that small class sizes have several advantages. For instance, Muennig and Woolf (2007) note that small class sizes with few students offer a healthier environment and these classes have an influence over the 
future health and life quality of those students. Moreover, very few psycho-social problems are reported in these classes. Therefore, spending money on education should not be regarded as a loss by politicians and governments. Instead, it should be seen as a socio-economic contribution.

Finn et al. (2003) conclude that having fewer students in a class is a positive influence over the quality of learning and behavioral change. In their empirical studies, these researchers mostly focused on the relationship between class size and student behaviour, and report that teachers' behaviour also influences student participation and interaction. They emphasize that small size classrooms decrease destructive behaviour displayed by primary education students as well as being better educational settings. Furthermore, they note that positive social behaviour increases, and social inactivity decreases in settings where students can be assessed individually. Furthermore, they state that teachers working with small groups are more tolerant and understanding of student behaviour and allow more time for student-teacher interaction. In addition, teachers have a better chance to offer tailored education in uncrowded classrooms. Taking all these reasons into account, the researchers explain that small classes with an increased sense of belonging, responsibility, interaction, and harmony are more beneficial educationally. Lastly, the researchers suggest conducting similar studies at different educational levels other than at the primary level, which is also a remarkable result with respect to the significance of this study.

According to Karabey (2004), who determined the number of students a class should host, effective interaction can be established and maintained with ten to fifteen students around a table. In such a setting, students can perceive and understand a task or text, and can follow each other's responses. Yet, it is almost impossible to build interaction among students in classes with sixty to one hundred students. So, a class with twenty five to thirty five students can be deemed an acceptable size to provide an average and standard learning setting. How many students a teacher can manage is as important as perception and comprehension when determining the ideal number of students in a class. A teacher's personality, instructional strategies, methods, and techniques also play a definitive role regarding the size of a class. Therefore, class size should not exceed twenty five in primary schools although it is not possible to determine a precise number.

As for Ogulmus and Ozdemir (1995), small size classrooms in primary schools are especially significant for the teaching of reading and mathematics skills, even though the ideal class size is also bound to other criteria, such as the topic being studied and the environment. According to the researchers, students in uncrowded classes take more responsibility, feel more pressure to participate in activities in and outside of the class, and contribute more to the flow of the lesson. In addition, as a byproduct, some students may start to think that they are in some way special. Therefore, the satisfaction these students experience in the class also elevates. Since there are fewer in these classes, students accept their classmates more easily. In addition, discipline problems are also scarce in small size classrooms. Moreover, the researchers report that teachers feel more positive and energetic, better student-teacher interaction is observed, and that tailoring instruction in accordance with students' needs and conducting student-centered teaching is easier in small size schools and classes, along with higher student success. In addition, in their study examining the Turkish education system and PISA results, Celen et al. (2011) relate the improvement of PISA 2009 results to a reduction in the number of students in classes and state that there is a direct correlation between the quality of education and the number of students per class.

Research findings point out that the number of students per class in primary schools is quite high in some areas and quite low in others, indicating an uneven distribution. Relevant studies in the literature report that there may be many reasons for this. For instance, Sahin (2006), notes that the number of students per class in rural areas of Kirsehir has decreased considerably (25-26 students) as a result of a decrease in the populated areas in the region. However, the same study concludes that density is still a reality (35-40 students) for schools in urban areas. Akpinar and Akbulut (2011) state that the number of students per teacher is higher than the national average in Sivas and that it is even more serious in certain counties. They note several reasons for this, such as teachers' reluctance to work in some counties due to differences across developmental levels, unfair assignment and appointment policies by the Ministry of National Education, and infrastructure problems of some schools. Similarly, Temiz (2007) reports that there are considerable differences between both the number of classrooms and the number of students per classroom even in the Izmir region, which offers one the most developed educational opportunities in Turkey. The author emphasizes that investment in areas where there is no need for classrooms should be stopped and unnecessary expense should be avoided. The reasons why there is a discrepancy across the distribution of students per class in Turkey should be carefully studied. Correct and effective steps can only be taken based on a comprehensive analysis of reasons.

In conclusion, an uneven distribution of students per class in rural and urban primary schools in Turkey is still an indicator of unequal opportunities in education. One fundamental problem, the inadequate number of classrooms has to be overcome first in order to improve the quality of education, which matters dramatically in terms of a country's development and social welfare. It is obvious that an even distribution of educational opportunities across the country 
and an elimination of regional inequality would contribute tremendously to national development in a country with a young population, such as Turkey. In today's world, where rapid technological advances are experienced, schools should have laboratories, libraries, and pull-out rooms, along with sufficient classrooms and teachers, and students should have optimum access to these facilities to ensure adequate provision of quality education. As a result, the present situation should be analyzed carefully, and investment and financing should be directed towards genuine needs. Turkish education policies focus mostly on quantity. However, research results indicate that urban primary schools generally have an adequate number of classrooms, which gives us all the more reason to emphasize quality over quantity in education.

\section{Acknowledgements}

This study was supported by the Anadolu University Scientific Research Projects Commission under grant No: 1504E153.

\section{References}

Ahmet, S. (2011). Does economic geography matter for Pakistan a spatial exploratory analysis of income and education inequalities? Pakistan Development Review, 50(4), 929-953.

Akbulut, G. (2010). The situation education of population in Malatya province. Atatürk University Journal of Graduate School of Social Sciences, 14(1), 115-132.

Akkalkan, H. (2009). The relationship between the school size and the academic success, school attendance, discipline in Ankara city çankaya district. Master's Thesis, Ankara University, Ankara.

Akpinar, E., \& Akbulut, G. (2011). Educational characteristics of Sivas province. Erzincan University Institute of Social Sciences Journal, 4(1), 1-20.

Anselin, L. (1995). Local indicators of spatial association-LISA. Geographical Analysis, 27, 93-115. https://doi.org/10.1111/j.1538-4632.1995.tb00338.x

Aydin, A., Sarier, Y., \& Uysal, S. (2012). The comparative assessment of the results of PISA mathematical literacy in terms of socio-economic and socio-cultural variables. Education and Science, 37(164), 20-30.

Aydiner, A. (2006). In the process of full membership, European Union education policies and their effects on Turkish education system. Master Thesis, Gazi University Institute of Educational Sciences.

Basaran, İ. E. (1996). Turkey education system. Ankara: Yargici Press.

Baytekin C. (2001). Contemporary classroom and computer classroom environment, Sakarya University Journal of Educational Faculty, (2), 120-133.

Berberoglu, G., \& Kalender, İ. (2005). Investigation of student achievement across years, school types and regions: The SSE and PISA analyses. Educational Sciences and Practice, 22(4), 21-35.

Celen, F. K., Celik, A., \& Seferoglu, S. S. (2011). Turkish education system and PISA Results. Academic Information, 2-4 February 2011, Inonu University, Malatya.

Cingi, H., Kadilar, C., \& Kocberber, G. (2008). To examine the opportunities of primary and secondary education in Turkey and to suggest solutions to the determined problems. TUBITAK Project Report, Project No. 106K077.

Dincer, M. A., \& Kolasin, G. U. (2009). Determinants of inequality in student failure in Turkey, Education Reform Initiative, Istanbul: Sabancı University.

Elias, M., \& Rey, S. J. (2011). Educational performance and spatial convergence in Peru. Région Et Development, 33, 107-135.

Finn, J. D., Pannozzo, G. M., \& Achilles C. M. (2003). The "why’s" of class size: student behavior in small classes. Review of Educational Research, 73(3), 321-368. https://doi.org/10.3102/00346543073003321

Fuente, H. D. L, Rojas, C., Salado, M. J., Carrasco, J. A., \& Neutens, T. (2013). Socio-spatial inequality in education facilities in the concepción metropolitan area (Chile). Current Urban Studies, 1(4), 117-129. https://doi.org/10.4236/cus.2013.14013

Gedikoglu, T. (2005). Turkish education system in the process of European community: problems and solutions. Mersin University Journal of the Faculty of Education, 1(1), 66-80.

Grześkowiak, A. (2015). Spatial analysis of adults involvement in education in Poland. European Journal of Social Sciences Education and Research, 3(2), 59-68.

Guclu, M. (2002). The problem of crowded classes in primary education and the solution proposal. Eurasian Journal of 
Educational Research, 9, 52-58.

Isik, H. (2012). The physical layout of learning environments. M. Sisman and S. Turan (Eds). Classroom Management in (s. 62-75), Ankara: Pegem A Publishing.

Karabey, H. (2004). Educational structures: contemporary approaches to planning and designing the schools of the future, principles. Istanbul: Literatür Publishing.

Karacali, A. (2006). The evaluation of physical variables which efects classroom management. Gazi University Journal of Kırşehir Education Faculty, 7(1), 145-155.

Karakutuk, K., \& Tunc, B. (2004). School size-class size. Akdeniz University Journal of Education Faculty, 1(1), 9-22.

Kavak, C. (2009). Concept of innovation and basic indicators in the information economy. Academic Informatics 09-XI, Academic Informatics Conference Proclamations, 11-13 February, Harran University, Sanliurfa, 2009.

Kocberber, G., \&Kazancik, L. B. (2010). A novel approach towards the examination of educational opportunities at primary schools. Hacettepe University Journal of Education, 38, 165-176.

Kucukyilmaz, S., Aktas, S., \& Karadag, O. (2015). Classification and ranking of the cities in Turkey depending on the 2012/2013 formal Education Statistics. Journal of Research in Education and Teaching, 4(4), 98-108.

Muennig, P., \& Woolf, S., H. (2007). Health and economic benefits of reducing the number of students per classroom in US primary schools. American Journal of Public Health, 97(11), 2020-2027. https://doi.org/10.2105/AJPH.2006.105478

Ogulmus, S., \& Ozdemir, S. (1995). The impact of class and school size on students. Education Management, 1(2), 261-271.

Onder, H. H., Gul, M., \& Erguldurenler, G. (2013). Using ergonomic rules in education environment and a study on ideal class. Journal of Suleyman Demirel University Institute of Social Sciences, Special Volume on Office Management, 41-55.

Sahin, A. (2006). Primary schools at Kirsehır from past to present. Gazi University Journal of Kırşehir Education Faculty, 6(2), 269-279.

Sarier, Y. (2010). An evaluation of equal opportunities in education in the light of high school entrance exams (OKS-SBS) and PISA results. Journal of Kirşehir Education Faculty, 11(3), 107-129.

Temiz, N. (2007). Use of statistics in GIS. Süleyman Demirel University Journal of Science, 2(2), 273-281.

The Ministry of National Education Directorate General for Basic Education (2012). School conversions. Retrieved from http://tegm.meb.gov.tr/meb_iys_dosyalar/2012_08/28113239_okuldnmleri.pdf

Webster, T. (2000). Introduction universal primary education-the ever receding goal: globalization of education policies: extent of external influences on contemporary universal primary education policies in Papua New Guinea. University of Papua New Guinea Press. Retrieved from http://www.pngbuai.com/300socialsciences/education/policy/globalization/ ed-global-1.html

Willson, R. W. (2008). In-class-online hybrid methods of teaching planning theory assessing impacts on discussion and learning. Journal of Planning Education and Research, 28, 237-246. https://doi.org/10.1177/0739456X08324286

Wordbank (2005). Education sector study-sustainable pathways to on effective, equitable and efficient education system for preschool through secondary school education. Word Bank.

Yaman, E. (2006). One dimension of the problems of the education system: large classes and classroom management. Journal of Turkish Educational Sciences, 4(3), 1-16.

Yılmaz, K., \& Altınkurt, Y. (2011). Prospective teachers' views about the problems of Turkish educational system. International Journal of Human Sciences, 8(1), 942-973.

\section{Copyrights}

Copyright for this article is retained by the author(s), with first publication rights granted to the journal.

This is an open-access article distributed under the terms and conditions of the Creative Commons Attribution license which permits unrestricted use, distribution, and reproduction in any medium, provided the original work is properly cited. 